\title{
The Analysis on the Influence Mechanism of Guizhou's Urban-rural Digital Gap to the Urbanization Process and City Economy
}

\author{
Bingsheng Guo \\ School of Economics, Wuhan University of Technology, Wuhan, 430070 China
}

\begin{abstract}
Urban-rural digital gap has become the obvious obstacle of urbanization process and city economy. And the influence of the urban-rural digital gap to urbanization has also appeared. Based on the analysis of influence of the urbanrural digital gap in Guizhou province to the urbanization, this paper focused on the influence mechanism of Guizhou's urban-rural digital gap to the urbanization.
\end{abstract}

Keywords-urban-rural digital gap; influence mechanism; urbanization process; city economy.

\section{INTRODUCTION}

Urban-rural digital gap in Guizhou province nut only hindered the upgrading of industrial structure, but also restrained the development of the rural economy. As well as impeded the improvement of living standards, the expanding space of the cities, except these, it also interfered the expansion of the scale of the city and the increasing of the number of cities, so as to slow down the development of Guizhou province urbanization. Judging from the changes in recent years, the urban-rural digital gap in Guizhou province keeps expanding, it goes against the process of urbanization. Speed up urbanization rates in Guizhou province has become a urgent demand of response to the plan of large-scale development of the western region as well as the promotion to the social and economic developments. We must quickly narrow the digital gap between urban and rural areas in Guizhou, in order to promote the sustained, rapid and sound development of urbanization.

By constructing the system dynamics model, this article analyses the mechanism of urban-rural digital gap influencing the urbanization in Guizhou province. The elements that the system contains were determinate by the confirming of the system boundary. And the ways that the urban-rural digital gap affects the urbanization in Guizhou province was expounded. Finally the urbanization level under two different circumstances which are "not affected by the urban-rural digital gap" and "affected by the urbanrural digital gap" were compared. By doing this, the influence of urban-rural digital gap to the urbanization in Guizhou province was verified.

\section{LITERATURE REVIEW}

Donnermeyer and Hollifield(2003) considered that urban and rural digital gap would delay the modernization of rural communication technique, and prevented the rural dwellers to improve their thinking mode and values in [1].
By studying the spread process of Internet in the British countryside, Warren(2007) proved that the residents in rural areas were more likely to be rejected by the Digital Society and marginalized than the urban residents in [2]. On one hand, urban-rural digital gap hindered the process of modernization of the rural infrastructure; on the other hand, it impeded the rural residents to improve their behaviors. In the city space structure level, scholars generally agreed that the digital gap would cause the urban space division, and decrease the expansion of urban space. By researching on the spread of information communication technology in French in 1999, Poncet and Ripert (2007) present that digital gap will lead to the city space division, finally affect the pattern of urbanization [3]. Poncet and Ripert present that digital gap will lead to the city space division, finally affect the pattern of urbanization [4]. The gap of Internet space between super-large scale cities and other cities is the major aspects of the digital gap was found in [5].

It can be found that the research on the impacts of urban-rural digital divide to the urbanization is not deep enough. And there is no theory system on this. The study still remains in the surface layer, such as the performance of urban-rural digital divide to urbanization and influence factors. The causal chain and the internal influence mechanism have not been probed. The paper constructed a system dynamics model, in order to analyze the influence mechanism of urban-rural digital divide of urbanization.

\section{MODEL CONSTRUCTION}

Making some proper assume during the modeling can make the constructed model descript the practical system. It can also avoid some complex details which increased workload or influence simulation results at the same time. Therefore, some basic assumptions to support models is needed to simplified the model. In order to highlight the goal and focus on the main problems and main contradictions, we gave the following model hypothesizes which based on the steps of System Dynamic modeling.

The system of the influence of the urban-rural digital divide to the urbanization is a complex system which contains many elements and many circuits. Therefore, in this article, the system dynamics theory was used to Constructed "ways of Guizhou's urban-rural digital divide affect the urbanization" and "Guizhou's urban-rural digital divide affect the urbanization SD model". In order to analysis the system structure and the dynamic behavior of the internal feedback relations and study the influence 
mechanism of Guizhou's urban-rural digital divide of urbanization further.

The system of Guizhou's urban-rural digital gap influence urbanization is continually. In this article, we assume that the change of the situation in the Guizhou urban-rural digital gap effects on urbanization system is continuous. It means the system behavior changes are not random, but continuous and gradual.

Determination of the impact of Guizhou urban-rural digital gap on the urbanization system boundary.The external environment influenced the system behavior through the internal structure of the system. So, determining the boundary of the system reasonably and analyzes its structure is the key step of modeling the system. The boundary of the system formulated which parts should be delimited in the system model and which parts should not. According to purpose of modeling, the impact of Guizhou's urban-and rural digital gap on the urbanization system should include three parts: urban-rural digital gap subsystem, urbanization subsystem and coupling subsystem. According to the concept of urban-rural digital gap and urbanization, 19 system elements were determined. the elements in the urban-rural digital gap subsystem are: urban-rural information technology skills gap, urban-rural education gap , the technology gap between urban and rural areas, urban-rural information technology consumption gap, urban-rural information technology infrastructure investment gap, information technology software resources investment gap between urban and rural residents, basic education investment gap between urban and rural residents, and information technology skills training investment gap between urban and rural areas, the digital gap. The elements in the urbanization subsystem are: urban space scope, the level of industrial structure, the life level, information technology infrastructure level, urbanization. The elements in the coupled subsystems are: infrastructure construction, education development level, income level, information communication technology application, consumption level. The relationships among the three subsystems were shown in figure 1 .

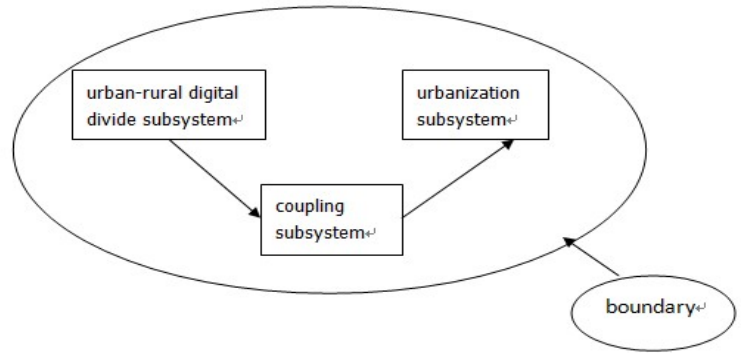

Fig.1: Boundary of the impact on urban-rural digital gap to Guizhou's urbanization SD model

Living standards = INTEG (living standards improve quantity, 818.54)

Living standards improvement $=$ consumption level $*$ $0.523129+368.027$-living standards
Urban space range $=$ INTEG (urban space range increment, 343)

Urban space range increment $=$ infrastructure level * $1.2602587+442.163$-city space range

Urbanization = INTEG (urbanization increment, 20.5522)

Urbanization increment $=$ level of industrial structure * $0.0722919+0.0080685+$ urban space range * infrastructure level $* 0.0197465+$ life level $* 0.00167063+$ 10.691-urbanization

Infrastructure level = INTEG (infrastructure level increment, 4.9)

Infrastructure level increment $=$ consumption level $*$ $0.00328823+5.02477$-infrastructure level

coupling subsystems

Education level = INTEG (education level increment education level decrement, 3.75)

Education level decrement = urban-rural education gap* 0.00359601

Education level increment $=$ consumption level * $0.00292297+0.0786729 *$ education fixed assets investment-1.63796-education level

The information technology infrastructure level = INTEG (information technology infrastructure level increment-information technology infrastructure level reduction, 1085)

The information technology infrastructure level reduction $=$ urban and rural technology gap $* 9.6471$

The information technology infrastructure level increment $=$ technology research and development input $* 12.3568+$ education level*92.3347-the level of technology

Education fixed assets investment $=$ consumption level * $0.0729673-1.47219$ e-006 * consumption level $\wedge 2+$ 1.55279e-008* consumption level^^3- 31.5437

Consumption level = INTEG (consumption level increment- consumption level reduction, 1431)

Consumption level reduction $=0.271283 *$ urban-rural information technology software resources investment gap

Consumption level incremental $=$ living standards * $1.32447+842.768$-consumption level

Technology research and development input = consumption level $* 5.43659+731.688$-consumption level

The industrial structure $=$ information technology infrastructure level * 3.62881 + 48.378

flow diagram of Guizhou urban-rural digital gap influence the urbanization SD model

Link up the 3 subsystems above, we could get the Shan'xi urban-rural digital gap influence urbanization SD model flow chart, which was shown in figure 2 as below. 


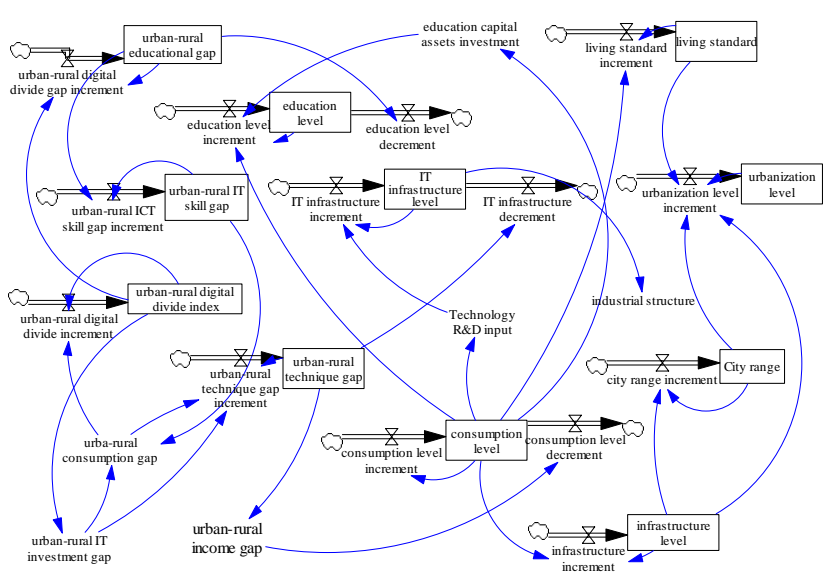

Fig.2: SD model flow diagram of the impact on urban-rural digital gap to urbanization in Guizhou

\section{RESULTS OF THE INFLUENCE OF GUIZHOU URBAN-RURAL DIGITAL GAP ON URBANIZATION}

As for the two senses "not affected by the urban-rural digital gap" and "affected by the urban-rural digital gap", the former state of the Guizhou urbanization is higher. In all the years for urbanization in the former states is higher than the later ones except the 2004. It means that the impact of urban-rural digital gap in Guizhou on the urbanization is notable. It hindered the improvement of urbanization, and slowed down the development of Guizhou province. AS seen from the concrete number, the urban-rural digital gap in Guizhou increased from 0.81 in 2004 to 5.24 in 2013, the average value of the urban-rural digital gap in Guizhou province was 3.0038. During this period, the average of the urbanization under the state of "Affected by the urban-rural digital gap" is 0.0822 percent than the state "not Affected by the urban-rural digital gap". The theory and method of system dynamics were used to build up the model of the influence of the urban-rural digital gap to the urbanization in Guizhou, and the model was tested. Then, the simulation was made to check the ways of the digital gap influence the urbanization. The results showed that the urban-rural digital gap hindered the development of urbanization in Guizhou obviously. There are three main ways of urban-rural digital gap hindering the development of the urbanization, such as hindering rural economic development, stopping the technological progress, and postponing the city expansion. If the existing state kept lasting, the urban-rural digital gap would expand and it would delay the development of urbanization in Guizhou. Narrowing the digital gap is an important way to promote the urbanization process and city economy. The government needs to take certain strategy for narrowing the economic gap, and promoting rural residents to use information technology, so as to narrow the digital gap, then promote the development of urbanization.

\section{REFERENCES}

[1] C. Ann Hollifield. Digital gap evidence in four rural towns [J]. IT\&Society, 1(4) , pp.107-117,2003.

[2] Martyn Warren. The digital vicious cycle: links between social disadvantage and dgital exclusion in rural areas [J]. Telecommunications Policy, (31), pp.374-388,2007.

[3] Patric Poncet, Blandine Ripert. Fractured space: a geographical reflection on the digital gap [J]. Geographical Journal, (68) , pp.1929,2007.

[4] S.Graham, S. Marvin. Splintering Urbanism: Networked Infrastructures, Technological Mobilities and the Urban Condition. Oxford: Oxford University Press, 2001.

[5] Wang Mingfeng. Internet using and the urbanization of China- the space aspect of digital gap [J]. sociology research, (6) , pp.112$135,2005$. 